\title{
Foraging behaviour of six calanoid copepods: observations and hydrodynamic analysis
}

\author{
Peter Tiselius ${ }^{1}$, Per R. Jonsson ${ }^{2}$ \\ ${ }^{1}$ Kristineberg Marine Biological Station, S-450 34 Fiskebäckskil, Sweden \\ ${ }^{2}$ Tjärnö Marine Biological Laboratory, PI. 2781, S-452 00 Strömstad, Sweden
}

\begin{abstract}
Swimming behaviour is described for 6 small copepods. Three types of feeding strategies were observed: (1) slow-moving or stationary suspension feeding (Temora longicornis, Pseudocalanus elongatus, and Paracalanus parvus); (2) fast swimming interrupted by sinking periods (Centropages typicus and C. hamatus); (3) motionless sinking combined with short jumps (Acartia clausi). Flow fields were similar for all suspension-feeding species but the anterior velocity gradient moved closer to the copepod in fast-swimming species. Theoretical hydrodynamic models were used to investigate costs and benefits of the different feeding strategies. Stationary suspension feeding is most efficient for capture of non-motile prey (algae) and fast swimming or sinking is better for capture of moving, rheotactic prey. Escape reaction distance of prey was calculated from theoretical models and from observed escape patterns of nauplii. Feeding behaviour is suggested as an important factor for prey selectivity of copepods.
\end{abstract}

\section{INTRODUCTION}

Feeding of zooplankton has been extensively studied with indirect methods, but the variable results imply that behaviour might be an important factor (Price 1988). Calanoid copepods have a complex behaviour and their swimming patterns affect both the way they avoid predation (Ohman 1988) and the way they gather food.

Conclusions on prey selection have traditionally been based on morphology of the mouthparts (Anraku \& Omori 1963, Nival \& Nival 1976, Schnack 1982) and disappearance of prey in feeding experiments (Frost 1977). Copepods able to feed on small prey, e.g. many autotrophs, were considered as suspension-feeding herbivores while species feeding on larger prey were considered as raptorial carnivores. The discovery of chemo- and mechanoreceptors and observations with high speed cinematography have revealed the abilities of remote sensing and complex handling of particles in most copepods studied (Koehl \& Strickler 1981, Paffenhöfer et al. 1982, Cowles \& Strickler 1983, Price et al. 1983, Price \& Paffenhöfer 1986a). Despite the perception of food particles immediately prior to ingestion many calanoid copepods show a monotonic generation of feeding currents from which prey are captured. This flow field is generally invariable within a species (Strickler 1982, Vanderploeg \& Paffenhöfer 1985), although microimpedance measurements have revealed some plasticity in frequency (Yule \& Crisp 1983, Price \& Paffenhöfer 1984, 1986b, Gill 1987) and amplitude (Yule \& Crisp 1983, Williamson 1987) of the moving mouthparts. To regulate their food intake, suspension-feeding copepods alter the time allocated to feeding movements (Cowles \& Strickler 1983, Price \& Paffenhöfer 1985, 1986b).

To catch moving, rheotactic prey, copepods have very different capabilities depending on the kind of behaviour shown. Besides waiting for prey (ambush predator; Gerritsen \& Strickler 1977) copepods can either swim towards the prey (cruising predator) or entrain the prey in their feeding currents (suspension feeder). Cruising behaviour both increases the encounter rate (Gerritsen \& Strickler 1977) and makes it possible to overtake escaping prey (Kerfoot 1978). Calanoids generally show a cruising behaviour whereas cyclopoids tend to be ambush predators. Cruising is thus used in obligate carnivores such as Euchaeta elongata (Yen 1985), Labidocera trispinosa (Landry \& Fagerness 1988) and Epischura nevadensis (Kerfoot 1978).

The dominant calanoid copepods in coastal waters are rather restricted in size $(0.6$ to $1.5 \mathrm{~mm})$ and many are traditionally viewed as suspension feeders on auto- 
trophs. They share the same environment and a varying behaviour might be a way of coexisting. Since swimming pattern strongly affects both food intake and vulnerability to predators (Greene 1988) it is an important characteristic likely to be affected by natural selection. In this study we present data on feeding behaviour of 6 small coastal copepods obtained by video recordings of free-swimming individuals. Basic velocity measurements (swimming and sinking speed) and time budgets for these behaviours are shown as well as reconstructions of flow fields. The data as well as theoretical considerations of hydrodynamics are used to discuss different feeding strategies and their implications for the role of each species in the pelagic food web.

\section{MATERIALS AND METHODS}

Copepods were collected in Kosterfjorden, on the west coast of Sweden, on 24 October and 7 November 1989. Temperature was $10^{\circ} \mathrm{C}$, salinity $27 \%$ and chlorophyll $<1.0 \mu \mathrm{g} \mathrm{l}^{-1}$ at the time of sampling. Collections were made by slowly towing a WP-2 net with closed cod end horizontally at 0 to $5 \mathrm{~m}$ and diluting the plankton in a 201 jar immediately after capture. All subsequent handling of animals was done at $12^{\circ} \mathrm{C}$ in a cold room.

Within 0.5 to $2 \mathrm{~h}$ of collection, individual adult females were sorted out and placed in $50 \mathrm{ml}$ beakers filled with surface water from the collection site. To quantify and describe the feeding behaviour, copepods were recorded on video tape (Panasonic CCD-F10 camera and NV-180 video-recorder). Filming was done at 3,6 or $12 \times$ magnification through a horizontally mounted Wild M5A, with the copepods in either a $10 \times$ $10 \times 2.5 \mathrm{~cm}$ (for Paracalanus parvus, Pseudocalanus elongatus, Acartia clausi and Temora longicornis) or a $30 \times 25 \times 12 \mathrm{~cm}$ (for Centropages hamatus and $C$. typicus) aquarium. Two light levels were used for each female and 2 to 5 individuals of each species were filmed. Individuals were always kept separate and this allowed us to compare the behaviour of the same individual at 2 light levels.

Light source was a cold light (150 W halogen lamp) which resulted in a light intensity of $220 \mu \mathrm{E} \mathrm{m}^{-2} \mathrm{~s}^{-1}$ ('high light') and, when filtered through a Corning CS 2-64 red filter, $1.7 \mu \mathrm{E} \mathrm{m} \mathrm{m}^{-2} \mathrm{~s}^{-1}$ ('low light). The combination of low light and a red filter made the apparent light intensity 10000 times lower for the copepods since they are 100 times less sensitive to light at $640 \mathrm{~nm}$ than white light (Stearns \& Forward 1984). The room was normally lit for the high light filming but kept dark when filming in low light. To account for possible endogenous feeding rhythms, copepods were filmed during daylight hours for the high light level and later the same evening and night for the low light level.

Video-recordings allowed us to determine when the feeding appendages were moving and this was assumed to represent active suspension feeding or swimming. Time allocated to suspension feeding or swimming was estimated by counting frames (for short feeding bouts) or noting the time from a simultaneously recorded timer. Jumps (defined as movements longer than 1 body length within $0.08 \mathrm{~s}$ ), loops (defined as $360^{\circ}$ vertical turns) and tilts (small, quick corrections of body position) were also noted.

Each female was followed for 5 to $15 \mathrm{~min}$ which resulted in a total recorded observation time of 42 to $376 \mathrm{~s}$ for each individual. Sequences where the copepod was closer than 2 body lengths from the walls of the aquarium or the surface were discarded, as well as those when the copepods went out of view.

For the study of flow field, frame-by-frame analyses of naturally occurring phytoplankton cells moving along flow lines were carried out on sequences of freeswimming copepods at $25 \times$ magnification at the high light level. To describe the 3 -dimensional flow field from 2-dimensional observations sequences with lateral and dorsal views were combined. To minimize the inevitable error of particles moving in and out of the focal plane, only particles with the highest velocity at a particular distance from the copepod were used for velocity measurements. Flow line velocities were calculated and velocity isolines were constructed. Calculation of flow available to the copepod was made by estimating the velocity isoarea as a one-base segment delimited by critical flow lines determined by the mouthparts and velocity isolines. Swimming and sinking speed was determined similarly by tracing the movements of the copepod on the monitor screen. Further details on filming technique and analysis are given in Jonsson \& Tiselius (1990).

The escape behaviour of nauplii encountered by Centropages typicus and $C$. hamatus was observed by video-recording of naturally occurring nauplii (ca $0.15 \mathrm{~mm})$ in aquaria $(30 \times 25 \times 12 \mathrm{~cm})$ together with one copepod female. Distance of the point of escape from the copepod head was marked on plastic sheets covering the monitor screen and escape velocity was measured by tracing nauplii frame by frame.

The copepods were seemingly unaffected by the handling and survived at least $3 \mathrm{~d}$ after the experiment. The copepods were then preserved in formalin $(4 \%)$ for length measurements.

Statistical analysis. The best way to analyse the effects of species and light condition on feeding time and bout length would be to calculate a nested 2-way ANOVA (analysis of variance) with measurements on 
individuals nested in the 2 orthogonal factors, species and light condition. However, tests for homogeneity of variances (Bartlett's test and $F_{\text {max }}$-test; Sokal \& Rohlf 1981) revealed that variances of feeding activity and bout length for the investigated copepod species were strongly heterogeneous. Transformation of data according to Taylor's power law (Elliott 1977) did not sufficiently reduce heterogeneity and the use of a nested 2way ANOVA was not attempted since the assumption of homogeneous variances was not fulfilled. Instead we firstly calculated the non-parametric analogue to 1-way ANOVA, the Kruskal-Wallis test (Sokal \& Rohlf 1981) for the 2 light intensities separately, and secondly made pairwise comparisons with significance level at 0.05 compensated for the number of comparisons.

\section{RESULTS}

\section{Behaviour and flow field}

Paracalanus parvus performed short feeding bouts ( 1.2 to $2.0 \mathrm{~s}$ mean duration) during 47 to $48 \%$ of the time and behaviour was the same in both high and low light (Table 1$)$. It rarely jumped (0 to 0.9 jumps $\mathrm{min}^{-1}$ ) but made some tilts ( 0 to 1.7 tilts $\min ^{-1}$ ) and one individual displayed a looping behaviour. P. parvus moved upward in an arc during feeding bouts with a swimming speed of $0.6 \mathrm{~mm} \mathrm{~s}^{-1}$ and subsequently sank with the same velocity (Table 2). Body orientation was nearly vertical both when swimming and sinking. The flow field was antero-ventrally directed and the

Table 1. Fraction of total observed time when mouthparts were moving, feeding bout length and jump frequency at low $(640$ nm, $1.7 \mu \mathrm{E} \mathrm{m}^{-2} \mathrm{~s}^{-1}$ ) and high (white light, $220 \mu \mathrm{E} \mathrm{m}^{-2} \mathrm{~s}^{-1}$ ) light levels

\begin{tabular}{|c|c|c|c|c|c|}
\hline Species & Light level & n & $\begin{array}{l}\text { Mouthparts moving } \\
\begin{array}{c}\text { (\% of total time }) \\
\pm \mathrm{SD}\end{array}\end{array}$ & $\begin{array}{c}\text { Feeding bout length } \\
\text { (s) } \\
\pm \mathrm{SD}\end{array}$ & $\begin{array}{c}\text { Jump frequency } \\
\text { (jumps } \min ^{-1} \text { ) } \\
\pm \mathrm{SD}\end{array}$ \\
\hline $\begin{array}{l}\text { Рaracalanus } \\
\text { parvus }\end{array}$ & $\begin{array}{l}\text { Low } \\
\text { High }\end{array}$ & $\begin{array}{l}3 \\
3\end{array}$ & $\begin{array}{l}47 \pm 17 \\
48 \pm 15\end{array}$ & $\begin{array}{l}2.0 \pm 1.4 \\
1.2 \pm 0.6\end{array}$ & $\begin{array}{l}0.3 \pm 0.5 \\
0.9 \pm 0.8\end{array}$ \\
\hline $\begin{array}{l}\text { Pseudocalanus } \\
\text { elongatus }\end{array}$ & $\begin{array}{l}\text { Low } \\
\text { High }\end{array}$ & $\begin{array}{l}2 \\
2\end{array}$ & $\begin{array}{l}55 \pm 21 \\
84 \pm 0\end{array}$ & $\begin{aligned} 9.1 & \pm 8.3 \\
18 & \pm 0.6\end{aligned}$ & $\begin{array}{l}4.0 \\
0\end{array}$ \\
\hline $\begin{array}{l}\text { Temora } \\
\text { longicornis }\end{array}$ & $\begin{array}{l}\text { Low } \\
\text { High }\end{array}$ & $\begin{array}{l}3 \\
2\end{array}$ & $\begin{array}{l}99 \pm 0 \\
99 \pm 0\end{array}$ & $\begin{array}{l}9.1+1.2 \\
8.7 \pm 0.7\end{array}$ & $\begin{array}{l}6.6 \pm 2.1 \\
6.4 \pm 0.9\end{array}$ \\
\hline $\begin{array}{l}\text { Centropages } \\
\text { typicus }\end{array}$ & $\begin{array}{l}\text { Low } \\
\text { High }\end{array}$ & $\begin{array}{l}3 \\
2\end{array}$ & $\begin{array}{l}58 \pm 6 \\
42 \pm 2\end{array}$ & $\begin{array}{l}4.0 \pm 0.3 \\
1.9 \pm 0.5\end{array}$ & $\begin{array}{l}0.8 \pm 0.3 \\
2.7 \pm 1.8\end{array}$ \\
\hline $\begin{array}{l}\text { Centropages } \\
\text { hamatus }\end{array}$ & $\begin{array}{l}\text { Low } \\
\text { High }\end{array}$ & $\begin{array}{l}2 \\
2\end{array}$ & $\begin{array}{l}41 \pm 4 \\
27 \pm 1\end{array}$ & $\begin{array}{l}0.6 \pm 0.1 \\
0.4 \pm 0.0\end{array}$ & $\begin{array}{c}0 \\
14 \pm 7.5\end{array}$ \\
\hline $\begin{array}{l}\text { Acartia } \\
\text { clausi }\end{array}$ & $\begin{array}{l}\text { Low } \\
\text { High }\end{array}$ & $\begin{array}{l}3 \\
3\end{array}$ & $\begin{array}{c}0 \\
0.6 \pm 1.1\end{array}$ & $\begin{array}{l}- \\
-\end{array}$ & $\begin{array}{l}54 \pm 24 \\
19 \pm 11\end{array}$ \\
\hline
\end{tabular}

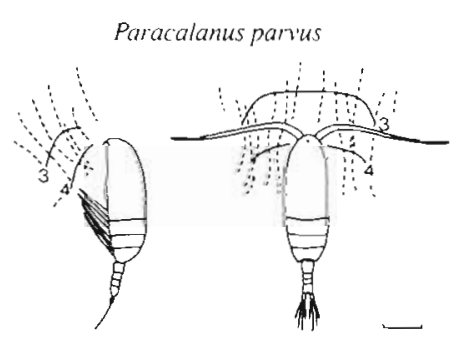

Centropages rypicus

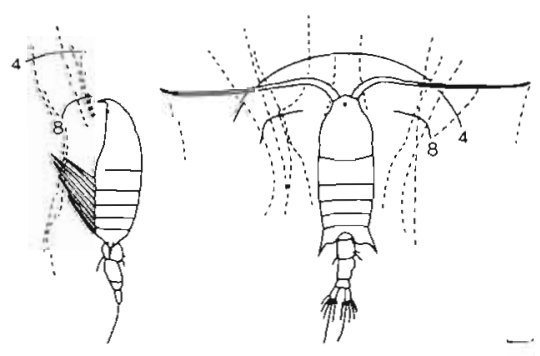

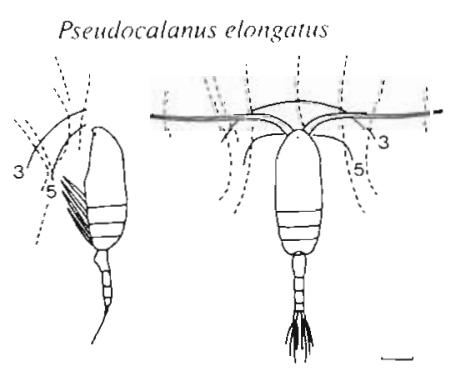

Centropages hamains

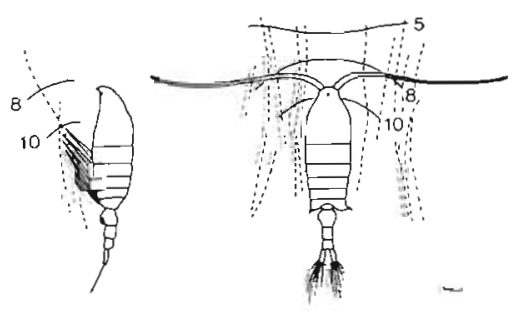

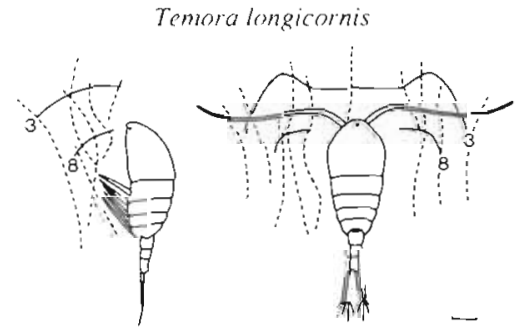

Fig. 1. Flow fields based on tracing of particles. Broken lines indicate trajectories of single particles and continuous isolines show flow velocity $\left(\mathrm{mm} \mathrm{s}^{-1}\right)$ relative to the copepod. Scale bar $=0.2 \mathrm{~mm}$ 
Table 2. Swimming and sinking velocities measured on copepods swimming vertically and sinking with body oriented horizontally (Centropages typicus and C. hamatus) or vertically with tail down (other species)

\begin{tabular}{|c|c|c|c|c|}
\hline Species & $n$ & $\begin{array}{l}\text { Swimming } \\
\text { velocity } \\
\left(\mathrm{mm} \mathrm{s}^{-1}\right) \\
\pm \mathrm{SD}\end{array}$ & $\begin{array}{l}\text { Sinking } \\
\text { velocity } \\
\left(\mathrm{mm} \mathrm{s}^{-1}\right) \\
\pm \mathrm{SD}\end{array}$ & $\begin{array}{l}\text { Cephalothorax } \\
\text { length } \\
\text { (mm) } \\
\pm \mathrm{SD}\end{array}$ \\
\hline $\begin{array}{l}\text { Paracalanus } \\
\text { parvus }\end{array}$ & 2 & $0.6 \pm 0.1$ & $0.6 \pm 0.1$ & $0.67 \pm 0.01$ \\
\hline $\begin{array}{l}\text { Pseudocalanus } \\
\text { elongatus }\end{array}$ & 2 & $0.5 \pm 0.0$ & $1.1 \pm 0.0$ & $0.92 \pm 0.00$ \\
\hline $\begin{array}{l}\text { Temora } \\
\text { longicornis }\end{array}$ & 2 & - & $2.5 \pm 0.4^{a}$ & $0.97 \pm 0.01$ \\
\hline $\begin{array}{l}\text { Centropages } \\
\text { typicus }\end{array}$ & 3 & $1.9 \pm 0.2$ & $1.0 \pm 0.1$ & $1.27 \pm 0.06$ \\
\hline $\begin{array}{l}\text { Centropages } \\
\text { hamatus }\end{array}$ & 3 & $7.2 \pm 2.7$ & $1.4 \pm 0.5$ & $1.03 \pm 0.03$ \\
\hline $\begin{array}{l}\text { Acartia } \\
\text { clausi }\end{array}$ & 3 & - & $0.3 \pm 0.0$ & $0.91 \pm 0.04$ \\
\hline
\end{tabular}

Table 3. Total flow passing by the copepods based on area of isosurfaces and flow velocities given in Fig. 1

\begin{tabular}{|lccc|}
\hline Species & $\begin{array}{c}\text { Isosurface } \\
\left(\mathrm{mm}^{2}\right)\end{array}$ & $\begin{array}{c}\text { Velocity } \\
\left(\mathrm{mm} \mathrm{s}^{-1}\right)\end{array}$ & $\begin{array}{c}\text { Flow } \\
\left(\mathrm{ml} \mathrm{d}^{-1}\right)\end{array}$ \\
\hline Paracalanus parvus & 0.103 & 3 & 27 \\
Pseudocalanus elongatus & 0.099 & 3 & 25 \\
Temora longicornis & 0.515 & 3 & 133 \\
Centropages typicus & 0.277 & 4 & 96 \\
Centropages hamatus & 0.186 & 8 & 129 \\
\hline
\end{tabular}

observed maximum flow velocity was relatively low, $4 \mathrm{~mm} \mathrm{~s}^{-1}$ (Fig. 1), resulting in a flow of $27 \mathrm{ml} \mathrm{d}^{-1}$ (Table 3).

Pseudocalanus elongatus spent 55 to $84 \%$ of the time in long feeding bouts, lasting 9 to $18 \mathrm{~s}$ each (Table 1 ). It rarely jumped according to our definition but the typical behaviour was frequent tilts ( 5 to 25 tilts $\mathrm{min}^{-1}$ ) changing the direction of motion. Both time allocated to feeding and bout length were longer in low light. Swimming velocity was $0.5 \mathrm{~mm} \mathrm{~s}^{-1}$ and, when not suspension feeding, copepods sank at $1.1 \mathrm{~mm} \mathrm{~s}^{-1}$ (Table 2). Body orientation was always constant with feeding appendages pointing obliquely upwards and $P$. elongatus moved mainly horizontally or slowly rising. Flow field and flow $\left(25 \mathrm{ml} \mathrm{d}^{-1}\right)$ were similar to Paracalanus parvus with a maximum flow velocity of $5 \mathrm{~mm} \mathrm{~s}^{-1}$ (Fig. 1)

Temora longicornis showed continuous suspension feeding ( $>99 \%$ of the time) and was never observed sinking. It was virtually immobile while performing long 'feeding bouts' $(8.7$ to $9.0 \mathrm{~s}$ duration) and jump frequency was 6.5 jumps $\mathrm{min}^{-1}$ (Table 1). No loops and only very small corrections of body orientation were observed. The feeding behaviour was not affected by changing light regimes. During suspension feeding the individual remained vertically oriented and slowly drifted horizontally or slightly upward. The strong and wide flow field was antero-ventrally directed with a unique lateral maximum coinciding with the distal parts of the feeding appendages in the power stroke (Fig. 1). The estimated flow was the highest of all species, $133 \mathrm{ml} \mathrm{d}^{-1}$ (Table 3 ).

Centropages typicus had longer feeding bouts ( 1.9 to $4.0 \mathrm{~s})$, the longest in low light. Longer time was also spent suspension feeding in low light, 58 vs $42 \%$ in high light (Table 1). Jump frequency was low 10.8 jumps min $^{-1}$ ) in low light and 2.7 jumps min $^{-1}$ in high light. One individual showed a looping behaviour $\{6.9$ loops $\min ^{-1}$ ). The general behaviour was similar to $C$. hamatus with long horizontally oriented sinking periods (sinking velocity $1.0 \mathrm{~mm} \mathrm{~s}^{-1}$ ) followed by upward swimming, $1.9 \mathrm{~mm} \mathrm{~s}^{-1}$ (Table 2). C. typicus showed a strong photokinetic response and sank when light came from above but swam up to the surface when a lid was placed on top of the aquarium. Flow field was wide and anteriorly directed (Fig. 1) and flow was $96 \mathrm{ml} \mathrm{d}^{-1}$ (Table 3).

Centropages hamatus showed a behaviour with short ( 0.4 to $0.6 \mathrm{~s}$ ) feeding bouts and 27 to $41 \%$ of the time spent in suspension feeding (Table 1). The time spent suspension feeding was longer in low light. No jumps was observed at low light but a frequency of 14 jumps $\min ^{-1}$ was found in high light. The high frequency of short feeding bouts made the behaviour look somewhat like that of Acartia clausi. Furthermore, the long periods of sinking sometimes included apparent catching movements with the mouth parts, similar to $A$. clausi. Body orientation was vertical at the start of a feeding bout and then the individual moved slowly in an arc or swam fast straight upwards (up to $7.2 \mathrm{~mm} \mathrm{~s}^{-1}$ ). The copepod sank with a horizontal orientation $\left(1.4 \mathrm{~mm} \mathrm{~s}^{-1}\right)$ with its tail pointed upward. Flow field was more anteriorly directed than in other species, probably due to the high swimming velocity (Fig. 1) resulting in a relatively high flow, $129 \mathrm{ml} \mathrm{d}^{-1}$ (Table 3 ).

Acartia clausi spent 87 to $99 \%$ of its time sinking, interrupted by frequent jumps (19 to 54 jumps min $^{-1}$, Table 1). Jump frequency was markedly higher in low light. The swift jumps, about 3 body lengths long, usually kept the copepod in the same vertical position. Occasionally while sinking. A. clausi made movements with its feeding appendages, quite different from suspension-feeding movements, and apparently this represented a raptorial behaviour when sensing jndividual objects (Jonsson \& Tiselius 1990). No suspension-feed- 
Table 4. Statistical analysis of time budget measurements by pairwise comparisons (Kruskal-Wallis test). Upper diagonal: observations in high light; lower: in low light. Significance at $\mathrm{p}<0.05(\bullet)$ or non-significance (ns) is showed for time of mouthpart movement and for feeding bout length before and after the slash respectively

\begin{tabular}{|lcccc|}
\hline & $P$. & $P$. & $C$ & $C$. \\
& parvus & $\begin{array}{c}C \text { elongatus } \\
\text { typicus }\end{array}$ & hamatus \\
\hline P. parvus & & $\cdot / \cdot$ & $\mathrm{ns} / \mathrm{ns}$ & $\cdot / \cdot$ \\
P. elongatus & $\mathrm{ns} / \mathrm{ns}$ & & $\cdot / \cdot$ & $\cdot \cdot$ \\
C. typicus & $\mathrm{ns} / \cdot$ & $\mathrm{ns} / \mathrm{ns}$ & & $\cdot / \cdot$ \\
C. hamatus & $\cdot / \cdot$ & $\mathrm{ns} / \cdot$ & $\cdot / \cdot$ & \\
\hline
\end{tabular}

ing movements was observed and hence no swimming speed or flow field was determined. Sinking started with the body oriented horizontally and it gradually turned vertical, tail down. Sinking speed was $0.27 \mathrm{~mm}$ $\mathrm{s}^{-1}$ when vertical orientation was reached.

The differences between feeding time at low or high light levels were significant (U-test, $\mathrm{p}<0.05$ ) only in Centropages typicus and C. hamatus and differences in bout length at the 2 light levels were significant for Pseudocalanus elongatus and C. typicus. Interspecies comparisons of feeding time and bout length exclude Temora longicornis and Acartia clausi which always were significantly different (U-test, $\mathrm{p}<0.05$ ) from the rest. All comparisons except Paracalanus parvus- $C$. typicus were significantly different in both respects at high light levels (Table 4). At low light, neither feeding time nor bout length were different in $P$. parvus- $P$. elongatus and C. typicus-P. elongatus and the feeding time did not differ between $P$. parvus-C. typicus and $P$. elongatus-C. hamatus.

\section{Flow during sinking}

At the low Reynolds number characterizing sinking copepods $(<1)$, the boundary layer around the copepod is considerable and water is affected many body lengths away. Fig. 2 shows that the velocity gradient around sinking individuals of Centropages typicus was modest at the observed sinking velocities as compared to the flow fields generated by beating mouthparts.

\section{Escape of nauplii}

When nauplii were entrained in the flow field of Centropages typicus or approached by cruising $C$. hamatus they responded by vigorously swimming away with mean escape velocity $20.3 \pm 7.2 \mathrm{~mm} \mathrm{~s}^{-1}$. Fig. 3 shows the location of initial escape response of

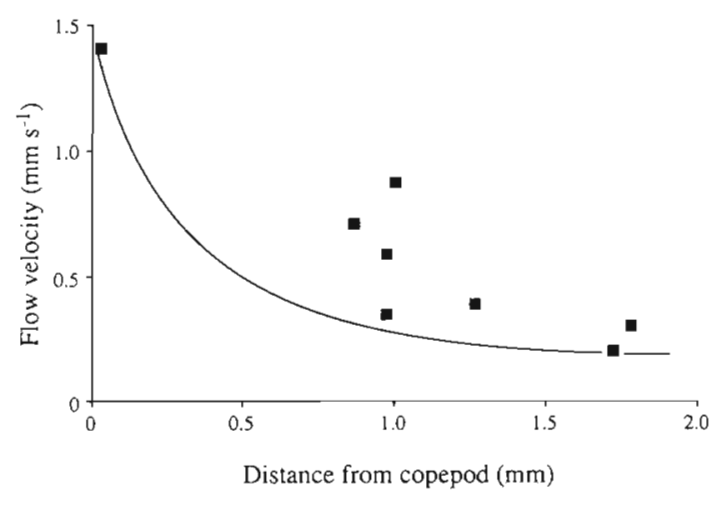

Fig. 2. Centropages typicus. Velocity gradient from body surface due to viscosity close to a sinking specimen (๘). Solid line represents prediction from Eq. (4)

nauplii relative to the copepod. Mean reaction distance was $0.92 \pm 0.13$ and $0.57 \pm 0.1 \mathrm{~mm}$ for $C$. typicus and C. hamatus, respectively.

\section{DISCUSSION}

The aim of this paper is to compare foraging behaviour of 6 small coexisting copepods and point to possible causes of observed differences. Even though the parameters studied certainly were insufficient to resolve the complicated behaviour of these 6 species, they still revealed important differences. We were not

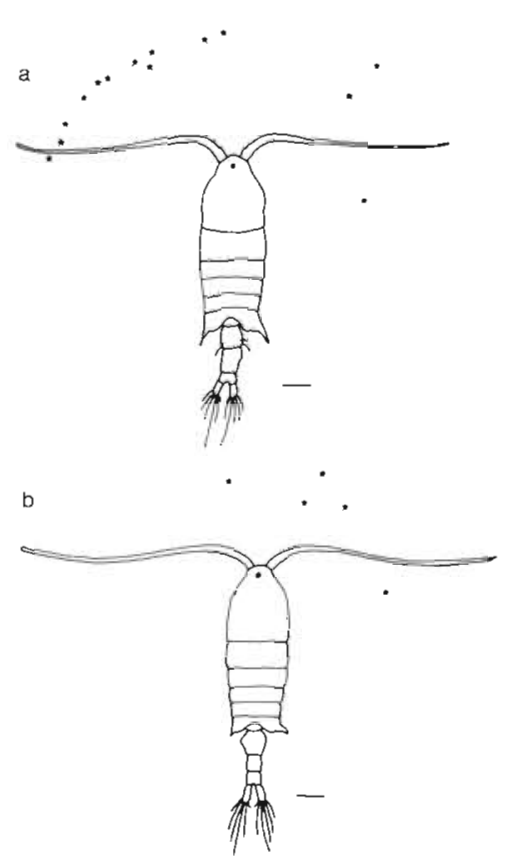

Fig. 3. Reaction response of nauplii in front of (a) a slowly swimming Centropages typicus and (b) a fast swimming $C$. hamatus. Symbols $(\star)$ mark the point where the nauplii made an escape reaction. Scale bar $=0.2 \mathrm{~mm}$ 
able to find one single feature that could separate all 6 species, but the combination of feeding time and bout length (Table 1) was sufficient. We are aware that copepods may show different behaviours faced with different food environments (Jonsson \& Tiselius 1990), but we believe that the basic behavioural characteristics are retained and can be studied by our simple method.

\section{Time budget}

The time budget analysis of behaviour shows a marked difference in the time allocated to movement of mouthparts among the 6 copepod species studied Acartia clausi rarely moves its mouthparts, while they are continually used in Temora longicornis to create water flow. Between these extremes Pseudocalanus elongatus, Centropages typicus, Paracalanus parvus and $C$. hamaus allocate decreasing time to mouthpart movement (Table 1). Gill (1987) found similar proportions of time allocated to beating of the second antennae in tethered $T$. longicornis $(100 \%)$, P. elongatus $(52 \%), C$. hamatus $(46 \%)$ and $A$. clausi $(14 \%)$, and Cowles \& Strickler (1983) observed that free swimming C. typicus spent 50 to $90 \%$ of the time moving mouthparts.

We suggest that, apart from food availability (Jonsson \& Tiselius 1990), the general time allocated to mouth part activity may be a function of the foraging strategy and the requirement to keep the depth position in the water column. Continual beating of mouthparts by Temora longicornis produces an upward thrust that just balances downward sinking, and the result is a constant suction of water towards the stationary copepod. This strategy seems suitable for suspension feeding on small slow-moving prey. A. clausi sinks passively through the water, possibly in search for large prey which are remotely detected as described for A. tonsa (Jonsson \& Tiselius 1990). Movement of mouthparts is here mostly restricted to attempts to capture detected prey. Occasional bursts of rapid swimming upwards help $A$. clausi to maintain its depth position.

Study of Centropages species was most difficult due to their variable behaviour and high swimming velocities. The small aquarium and problems in following individuals probably biased our results and underestimated their fast swimming behaviour. Gauld (1966) stated that Centropages (probably C. hamatus) spends much more of its time in horizontal movement than Calanus, and it clearly can switch between slow-swimming and fast-swimming modes (Greene 1988). We observed that both Centropages species displayed high swimming velocities but that bout length was short in C. hamatus. Both C. typicus and C. hamatus probably have a raptorial component in their feeding behaviour (Wiadnyana \& Rassoulzadegan 1989) although we only rarely observed capture of large items. Particularly $C$. hamatus spent most of the time sinking, often with the body horizontally oriented. The typical pointing tail might aid in keeping a horizontal position which maximizes the sensory area during descent. This behaviour is similar to that of $A$. clausi and $A$. tonsa, but in contrast to these species C. hamatus showed fast cruising (ca $5 \mathrm{~mm} \mathrm{~s}^{-1}$ ) between sinking events.

Pseudocalanus elongatus and Paracalanus parvus seem to have a feeding behaviour adapted to suspension feeding of small prey (Price et al. 1983, Buskey 1984, Wong 1988). This is most marked in P. elongatus which allocates most of its time to movement of mouthparts. The feeding currents result in an upwards thrust and feeding bouts are interspersed with times of sinking, which give the copepod an almost constant net vertical position. The same basic pattern is found for $P$. parvus, but since this copepod is smaller and sinks slower it has to spend more time sinking to maintain its net vertical position. From Tables 1 and 2 it is clear that the vertical components of movement are of comparable size for the 4 species that show a well-defined, regular cycle of upward swimming and sinking. We speculate that the allocation of time between sinking and upward movement is selected according to the relation between upward thrust and gravitational force in order to reduce vertical drift due to feeding.

How do our observations of behaviour compare with earlier reports on feeding habits based on morphology of the mouth parts? As pointed out by Gauld (1966), the second maxillae (M2), which intercept prey, show different degrees of complexity among copepod species which may be correlated to feeding characteristics. Temora longicornis, Pseudocalanus elongatus and Paracalanus parvus all have non-differentiated M2 and they also displayed a monotonous, suspension-feeding behaviour suitable for catching small, non-motile prey The mesh size is small and the tips of the M2 lie just posterior to the mouth when the $\mathrm{M} 2$ is at rest. The combining motion of the first maxillae (M1) collect particles and push them to the mouth (Price et al. 1983).

The M2 can have a dual function in omnivores since it is divided into a fine mesh, basal part and a raptorial, distal part (Gauld 1966). This kind of complex M2 is found in the Centropages species and Acartia clausi which also show a more diverse feeding behaviour. When at rest the basal setae are close to the mouth and within reach of the endites of the $M 1$, whereas the distal setae are not. This is most pronounced in Centropages (Cowles \& Strickler 1983) where the distal parts are prehensile and grasp prey (Anraku \& Omori 1963). However, this part of the M2 cannot filter small particles efficiently because of the wide mesh and the 
particles efficiently because of the wide mesh and the fact that the setae are out of reach for the M1 endites (Gauld 1966). In Acartia, the scooping motion (Rosenberg 1980) and long curved M2 setae (Paffenhöfer \& Stearns 1988) are suitable for catching large, motile prey (Jonsson \& Tiselius 1990). Since both these species can live on microflagellates, small prey are probably collected by the basal parts of the M2 during slow swimming, even though this has not been described.

\section{Flow field}

In all the studied species except Acartia clausi the flow field is created by the second antennae, the first maxillae and the maxillipeds (Gauld 1966, Strickler 1984, Paffenhöfer \& Stearns 1988). The capture movements of $A$. clausi differ from the generation of flow field in that the thoracopods are involved (Rosenberg 1980). Except for Centropages hamatus, the flow fields were similar to the one described for free-swimming Eucalanus crassus (Strickler 1982): an antero-ventrally directed shear field with strong velocity gradients near the copepod. Velocity of the feeding currents are correlated to the size of copepods. The pronounced anteroventral flow has implications for the possibilities of prey detection by chemoreceptors. Since the main flow does not pass the first antennae (A1) before the mouthparts (Fig. 1) there is probably no advance detection of approaching prey by $\mathrm{A} 1$ and chemoreception has to be accomplished by receptors found on the mouthparts (Strickler 1984). This is supported by the finding that removal of the A1 did not affect feeding rates for Calanus pacificus (Landry 1980). However, if the copepod is swimming or sinking then the A1 might be an effective site of mechanoreceptors as observed in many species (Landry \& Fagerness 1988). The hydrodynamic signals produced by moving prey are not restricted to follow flow lines (as chemical signals in laminar flow). The direction of the flow field is therefore of less importance for the perception of hydrodynamic signals.

\section{Models}

The behaviours of the 6 studied copepod species suggest 3 different feeding strategies: (1) to remain stationary and generate a strong flow with the mouthparts, exemplified by Paracalanus parvus, Pseudocalanus elongatus and Temora longicornis; (2) to cruise through the water like Centropages hamatus; and (3) to sink through the water like Acartia clausi. To evaluate the benefits and costs we modeled the flow dynamics of the 3 feeding strategies.

A copepod with several appendages of complex shape and movements is difficult to model in detail, and we have resorted to simple abstractions. A stationary copepod may be viewed as a pump where water is sucked in from the anterior. This is done by applying a force on the water through the drag of the beating mouthparts. Greatly simplified, this can be described as a single force acting at a point in an infinite volume. In hydrodynamic theory this is one solution to Stoke's equation (Happel \& Brenner 1983) and the resulting flow field is depicted in Fig. $4 \mathrm{a}$. If we only consider a polar coordinate plane the velocity components $u_{r}$ and $\mathrm{u}_{\theta}$ at a point $(\mathrm{r}, \theta)$ are

$$
u_{r}=\frac{F}{8 \pi \mu r} 2 \cos \theta \text { and } u_{\theta}=\frac{F}{8 \pi \mu r} \sin \theta
$$

where $\mathrm{F}=$ force acting in origo along $\theta=0 ; \mu=$ dynamic viscosity; $r=$ distance from origo (Fig. $4 \mathrm{a}$ ). The local fluid velocity $u$ at a point $(r, \theta)$ is the vector sum

$$
u=\sqrt{u_{r}^{2}+u_{\theta}^{2}}
$$

The force applied by a copepod that remains more or less stationary during flow generation can roughly be calculated from the observed sinking velocities $\left(\mathrm{u}_{\text {sink }}\right)$ assuming that gravity balances drag force $(F)$ as

$$
\mathrm{F}=6 \mathrm{u}_{\text {sink }} \pi \mu \mathrm{a}
$$

where $\mathrm{a}=$ radius of the copepod (assumed to the spherical). The velocity gradients predicted by Eq. (1)

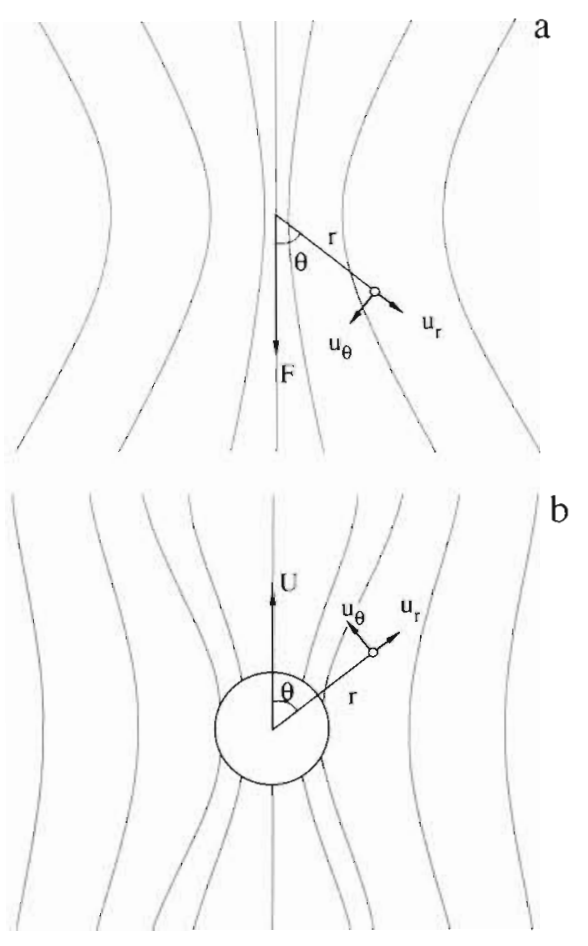

Fig. 4. Flow fields generated by a force (a) acting on a singular point and (b) generated by a translating sphere. Symbols used in the model (see text) are indicated 


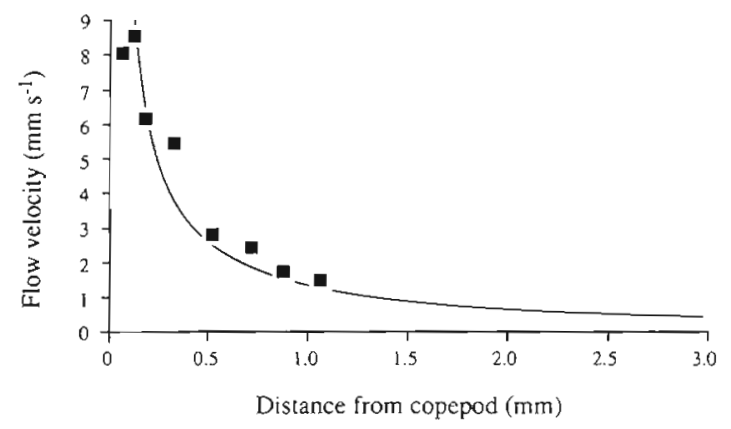

Fig. 5. Centropages typicus. Velocity gradient created by an almost stationary individual ( $)$ compared with model predictions calculated from Eqs. (1) and (3) (continuous line)

using the calculated force from Eq. (3) agree reasonably well with observations (Fig. 5); this also applies to the flow fields (Figs. 1 and 4).

To model a swimming or sinking copepod, a solution similar to Eq. (1) can be found for a translating sphere of radius a moving with velocity $U$ (Fig. 4b)

$$
u_{r}=-U \cos \theta\left(-\frac{3 a}{2 r}+\frac{a^{3}}{2 r^{3}}\right)
$$

and

$$
u_{\theta}=-U \sin \theta\left(-\frac{3 a}{4 r}-\frac{a^{3}}{4 r^{3}}\right)
$$

where $u_{r}$ and $u_{\theta}=$ velocity components at a point $(r, \theta)$ along and perpendicular to a radius vector (Happel \& Brenner 1983).

\section{Feeding strategies}

An interesting result from Eqs. (1) and (3) applies to copepods which are approximately stationary while suspension feeding. A copepod that can balance thrust from flow generation against gravity and thus remain stationary will be more efficient in terms of water flow per force than a copepod where thrust exceeds gravity which will cause the copepod to move through the water. This is because a moving copepod has to pay some of the force as drag. That flow past an organism is larger when the organism is attached relative to when it is swimming has been pointed out by Fenchel (1986) for protists and has been suggested for copepods which are 'tethered' by gravity (Strickler 1982, Emlet \& Strathman 1985). Large copepods like Neocalanus cristatus (Landry \& Fagerness 1988), Eucalanus crassus and E. monachus (Strickler 1982) or relatively heavy species, like Temora longicornis (Yule \& Crisp 1983), feed in this manner

A simple calculation may indicate the benefit of being stationary. If the capture area is proportional to the cross section of the copepod times swimming velocity $\left(u_{s w i m}\right)$, clearance $(Q)$ will be $Q_{s w i m}=u_{\text {swim }} a^{2} \pi$ (assuming complete retention). Considering the drag of the copepod (Eq. 3), a given force for thrust generation will result in $u_{s w 1 m}=F /(6 \pi \mu a)$ and substitution gives $Q_{\text {swim }}=F$ a $/(6 \mu)$. Assuming a stationary copepod and integrating $u_{\leftrightarrow}$ in Eq. (1) over the cross section, clearance is

$$
\mathrm{Q}_{\text {stat }}=\mathrm{F} \mathrm{a} /(4 \mu)
$$

The ratio $Q_{\text {stat }} / Q_{\text {swim }}$ is thus 1.5 and a stationary copepod should thus do $50 \%$ better than a swimming one. In reality the difference should be less since even a stationary copepod has to pay a drag cost because the body imposes a viscous resistance to the generated flow. There seem to be some constraints on the size of an organism for a 'gravitational tether' to work. Clearance rates of copepods seem to be approximately proportional to the square of body length (Ikeda 1977) which agrees well with the size-dependent metabolic rate (Ivlea 1980). If this relation is applied to the calculated flows and measured body widths (b) in this study, then clearance rate is $0.007 \times \mathrm{b}^{2} \mathrm{~m}^{3} \mathrm{~s}^{-1}$ which if substituted into Eq. (5) yields an estimation of the force, $\mathrm{F}_{\text {flow }}=$ $\mathrm{b} \times 5.6 \times 10^{-5} \mathrm{~N}$, required to generate feeding currents that will cover metabolic demands. $F_{\text {flow }}$ is thus a linear function of body width and will produce a thrust on the copepod. However, gravitational force $\left(\mathrm{F}_{\mathrm{g}}\right)$ should be proportional to the cube of body width approximately as

$$
F_{g}=\frac{b^{3} \pi \Delta \rho g}{6}
$$

where $\Delta \rho=$ density difference between copepod and the surrounding water; $g=$ acceleration due to gravity. If we assume a $\Delta \rho$ of $30 \mathrm{~kg} \mathrm{~m}^{-3}$ and examine the ratio between the 2 forces

$$
\frac{F_{\text {flow }}}{F_{g}}=\frac{3.36 \times 10^{-4}}{b^{2} \pi \Delta \rho g}
$$

it is obvious from Fig. 6 that when body width gets smaller than about $0.2 \mathrm{~mm}$, gravitational force becomes insignificant and drag is the dominant force opposing

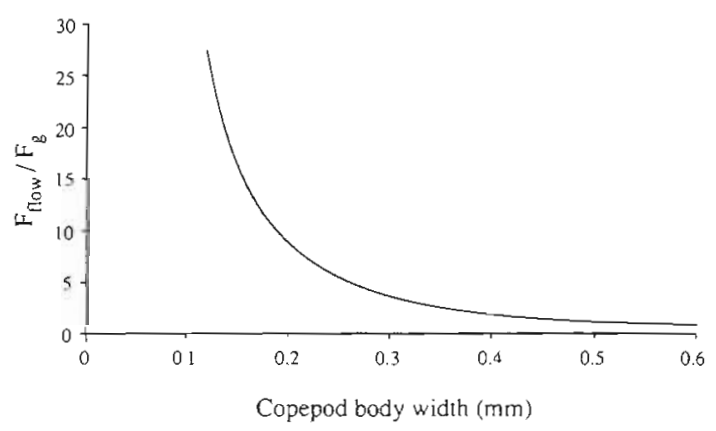

Fig. 6. Ratio between force required for the generation of feeding currents to cover metabolic demands $\left(F_{\text {flow }}\right)$ and force required to remain suspended $\left(F_{g}\right)$ as a function of copepod body width. See text for explanations 
the force produced by the beating mouthparts. This rough calculation indicates that gravitational tethering may be important in larger copepods and that copepods with a body width larger than $0.6 \mathrm{~mm}$ have to supply extra force to remain suspended. Of course, these limits will also be a function of body density which may be subject to adjustments and natural selection.

Many planktonic organisms show remote detection of moving objects (e.g. Kerfoot 1978, Haury et al. 1980, Jonsson \& Tiselius 1990). It is presently not known how remote detection in copepods functions but it seems probable that mechanoreceptors perceive the hydrodynamic disturbance associated with objects moving through water. It has also been demonstrated that planktonic organisms exhibit escape responses either elicited by flow fields (Singarajah 1969, Kirk \& Gilbert 1988) or moving objects (Haury et al, 1980). Of the possible properties of fluid motion that an organism could sense there are good theoretical arguments that fluid deformation and/or the rate of deformation are the important stimuli (Haury et al. 1980, Zaret \& Kerfoot 1980). With the models of a stationary and a moving suspension feeder (Eqs. 1 and 4) we can examine the rate of fluid deformation which may be measured as the velocity gradient in the flow fields. The velocity gradient, $\partial \mathrm{u} / \partial \mathrm{r}$, is the partial derivative of the local velocity with respect to distance and is for the stationary model in Eq. (1)

$$
\frac{\partial u}{\partial r}=-\frac{F}{8 \pi \mu r^{2}} \sqrt{4 \cos ^{2} \theta+\sin ^{2} \theta}
$$

and is for a translating sphere in Eq. (4)

$$
\begin{aligned}
\frac{\partial u}{\partial r}=\frac{U^{2}}{2 \sqrt{u_{r}^{2}+u_{\theta}^{2}}}[ & \cos ^{2} \theta\left(-\frac{9 a^{2}}{2 r^{3}}-\frac{3 a^{6}}{2 r^{7}}+\frac{6 a^{4}}{r^{5}}\right) \\
& \left.+\sin ^{2} \theta\left(-\frac{9 a^{2}}{8 r^{3}}-\frac{3 a^{6}}{8 r^{7}}-\frac{3 a^{4}}{2 r^{5}}\right)\right]
\end{aligned}
$$

We now assume that some prey can sense this rate of deformation and respond by escaping when the rate of deformation exceeds some threshold, $\partial \mathrm{u}^{*} / \partial \mathrm{r}$. In experiments with Centropages typicus and C. hamatus we found that nauplii escape at a deformation rate about $2 \mathrm{~s}^{-1}$. Inserting this $\partial \mathrm{u}^{*} / \partial \mathrm{r}$ into Eq. (8) it is possible to see how detection distance of the prey varies with maximum flow velocity (force applied) in a stationary copepod (Fig. 7). The faster the flow is, the farther away will a prey detect the copepod; on the other hand, if maximum flow velocity is sufficiently low, $\partial \mathrm{u} / \partial \mathrm{r}$ is never reached before the prey enters the copepod's capture volume. Obviously, the stationary feeding strategy where prey is captured through suction of water may be inefficient when trying to capture prey with powerful escape capabilities. However, if escape

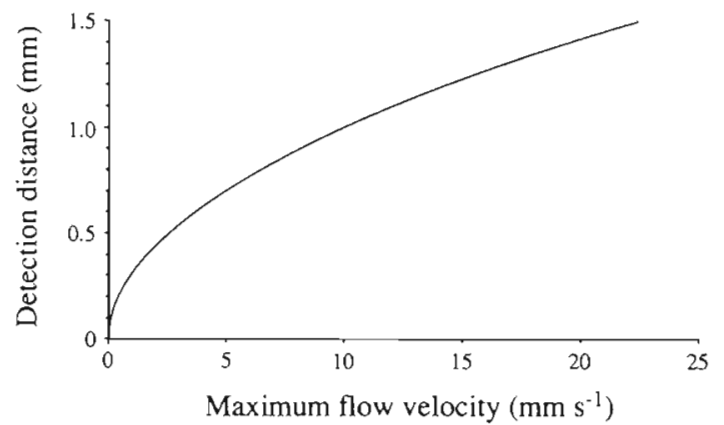

Fig. 7. Detection distance for a prey as a function of maximum flow velocity of a stationary copepod. Detection is assumed when rate of deformation (Eq. 8) exceeds $2 \mathrm{~s}^{-1}$ (calculated from Fig. 3)

velocity is low or reaction time of the prey is long it may still be entrained in the feeding currents.

We can also compare the distribution of deformation rates for a stationary and a moving predator which apply the same force on the fluid. Fig. 8 shows the ratio of the deformation rates along radius vectors with 3 different angles. Deformation rate is less in front of a moving predator but slightly greater at the sides. This would point to an advantage for a swimming predator when hunting for swift and sensitive prey. The scarce data on the 2 species of Centropages support this view where cruising $C$. hamatus could approach nauplii closer than could almost stationary $C$. typicus, although the applied force should be greater for $C$. hamatus. Other advantages for a moving predator is that the encounter rate with slow-moving prey increases (Gerritsen \& Strickler 1977).

Apart from the stationary or cruising strategies, a third feeding strategy is to sink passively through the water in search for prey. Jonsson \& Tiselius (1990) showed how sinking Acartia tonsa remotely detects and captures moving ciliates, and $A$. clausi in this study seemed to behave similarly. The 2 Centropages species also include this behaviour in their repertoir but the

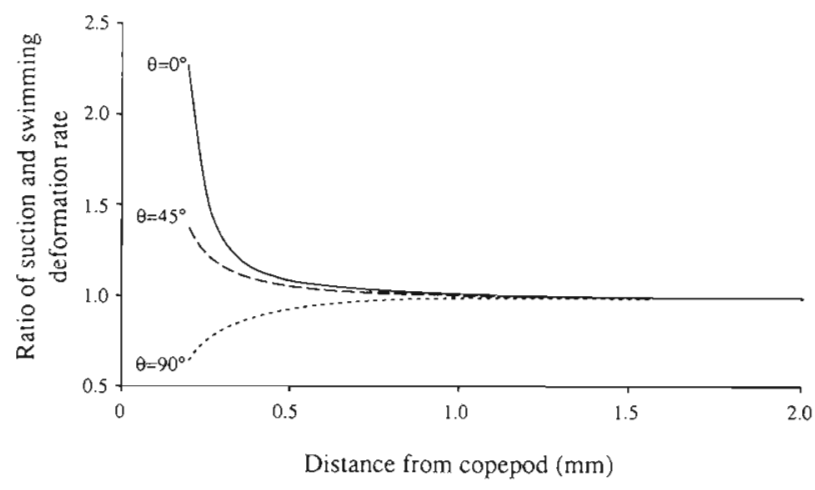

Fig. 8. Comparison of deformation rate around a translating sphere (Eq. 9) with that around a force acting at a point (Eq. 8), at 3 different angles $\left(0,45,90^{\circ}\right)$ 
significance is presently unknown. A possible advantage for a sinking predator is that the rate of deformation ahead of the body is kept very low. In Fig. 2 the velocity gradient for sinking $C$. typicus roughly corresponds to that predicted by Eq. (9). The sinking velocities measured for e.g. A. tonsa (Jonsson \& Tiselius 1990 ) and A. clausi would result in deformation rates that are everywhere lower than the critical $\partial \mathrm{u} / \partial \mathrm{r}$ measured for nauplii, and prey with this sensitivity would not detect the approaching predator.

\section{CONCLUSIONS}

Simple hydrodynamic models may help to analyse benefits and costs of different foraging strategies and to suggest valuable experiments. We identify in this study 3 feeding strategies for copepods.

(1) To remain more or less stationary during feeding by balancing gravitational force and thrust. This should theoretically maximize flow for a given force by minimizing drag costs. A stationary copepod may also reduce the risk of being detected by predators that use vision, e.g. fish.

(2) Cruising copepods increase encounter rate, particularly for slow-moving prey, and may reduce the rate of fluid deformation ahead and thus approach prey in a hydrodynamically quieter way than stationary feeders.

(3) Ambush predators sink passively with low velocity and generate very low deformation rates ensuring that prey are encountered within the predator's capture volume. Sinking predators should also be hydrodynamically quieter than stationary and cruising feeders, and thus attract less attention from predators responding to deformation rate.

Much of the future progress in the understanding of information exchange between predator and prey will depend on the correct identification of relevant hydrodynamic signals. In the present study we have assumed the rate of fluid deformation to be important for detection of moving objects and flow fields. One argument for this is that deformation rate should easily be perceived by mechanoreceptors where deformation rate is transduced into bending stress in sensory setae. The velocity difference sensed by a seta is deformation rate times length of seta. It may be speculated that the stress threshold in sensory setae which results in release of nerve impulses is a general property of mechanoreceptors and that differences in sensitivity are caused by differences in seta length and elasticity (Tautz 1979). Our paper illustrates the great need for physiological studies of how hydrodynamic disturbances are transduced into nerve impulses to resolve current hypotheses about interactions between planktonic predators and prey.
Acknowledgements. This study was supported by the National Swedish Environmental Protection Board (Grant 5312339-4) to P.T., and by the Swedish Natural Science Research Council through contract B-BU-1860-301 and the Helge Ax:son Johnson foundation to P.R.J

\section{LITERATURE CITED}

Anraku, M.. Omori, M. (1963). Preliminary survey of the relationship between the feeding habitat and the structure of the mouth-parts of marine copepods. Limnol. Oceanogr. 8 (1): 116-126

Buskey, E. J. (1984). Swimming pattern as an indicator of the roles of copepod sensory systems in the recognition of food. Mar Biol. 79: 165-175

Cowles, T. J., Strickler, J. R. (1983). Characterization of feeding activity patterns in the planktonic copepod Centropages typicus Kroyer under various food conditions. Limnol. Oceanogr. 28 (1): 106-115

Elliott, J. M. (1977). Some methods for the statistical analysis of samples of benthic invertebrates. Sci. Publ. No. 25, Freshwater Biological Association, Ferry House, U.K.

Emlet, R. B., Strathman, R. R. (1985). Gravity, drag, and feeding currents of small zooplankton. Science 228: $1016-1017$

Fenchel, T. (1986). Protozoan filter feeding. Prog. Protistology 1: $65-113$

Frost, B. W. (1977). Feeding behavior of Calanus pacificus in mixtures of food particles. Limnol. Oceanogr 22 (3): $472-491$

Gauld, D. T (1966). The swimming and feeding of planktonic copepods. In: Barnes, H. (ed.) Some contemporary studies in marine science. Allen and Unwin, London, p. 313-334

Gerritsen, J., Strickler, J. R. (1977). Encounter probabilities and community structure in zooplankton: a mathematical model. J. Fish. Res. Bd Can. 34: 73-82

Gill, C. W. (1987). Recording the beat pattern of the second antennae of calanoid copepods, with a microimpedance technique. Hydrobiologia 148: 73-78

Greene, C. H. (1988). Foraging tactics and prey-selection patterns of omnivorous and carnivorous calanoid copepods. Hydrobiologia 167/168: 295-302

Happel, J., Brenner, H. (1983). Low Reynolds number hydrodynamics. Martinus Nijhoff Publishers, Dordrecht

Haury, L. R., Kenyon, D. E., Brooks, J. R. (1980). Experimental evaluation of the avoidance reaction of Calanus finmarchicus. J. Plankton Res. 2 (3): 187-202

Ikeda, I (1977). Feeding rates of planktonic copepods from a tropical sea. J. exp. mar Biol. Ecol. 29: 263-277

Ivlea, I. V (1980). The dependence of crustacean respiration rate on body mass and habitat temperature. Int. Revue ges Hydrobiol. 65: 1-48

Jonsson, P. R., Tiselius, P. (1990). Feeding behaviour, prey detection and capture efficiency of the copepod Acartia tonsa feeding on planktonic ciliates. Mar. Ecol. Prog. Ser 60: $35-44$

Kerfoot, W. C. (1978). Combat between predatory copepods and their prey: Cyclops, Epischura, and Bosmind. Limnol. Oceanogr 23 (6): 1089-1102

Kirk, K. L., Gubert, J. J. (1988). Escape behavior of Polyarthra in response to artificial flow stimuli. Bull. mar. Sci. 43 (3) $551-560$

Koehl, M. A. R., Strickler, J. R. (1981). Copepod feedıng currents: food capture at low Reynolds number Limnol. Oceanogr. 26 (6): 1062-1073 
Landry, M. R. (1980). Detection of prey by Calanus pacificus: implications of the first antennae. Limnol. Oceanogr. 25 (3): $545-549$

Landry, M. R., Fagerness, V L. (1988). Behavioral and morphological influences on predatory interactions among marine copepods. Bull. mar. Sci. 43 (3): 509-529

Nival, P., Nival, S. (1976). Particle retention efficiencies of an herbivorous copepod, Acartia clausi (adult and copepodite stages): effects on grazing. Limnol. Oceanogr. 21 (1): 24-38

Ohman, M. D. (1988). Behavioral responses of zooplankton to predation. Bull. mar. Sci. 43 (3): 530-550

Paffenhöfer, G.-A., Stearns, D. E. (1988). Why is Acartia tonsa (Copepoda: Calanoida) restricted to nearshore environments? Mar. Ecol. Prog. Ser. 42: 33-38

Paffenhöfer, G. -A., Strickler, J. R., Alcaraz, M. (1982). Suspension-feeding by herbivorous calanoid copepods: a cinematographic study. Mar. Biol. 67: 193-199

Price, H. J. (1988). Feeding mechanisms in marine and freshwater zooplankton. Bull. mar. Sci. 43 (3): 327-343

Price, H. J., Paffenhöfer, G.-A. (1984). Effects of feeding experience in the copepod Eucalanus pileatus: a cinematographic study. Mar. Biol. 84: 35-40

Price, H. J., Paffenhofer, G.-A. (1985). Perception of food availability by calanoid copepods. Arch. Hydrobiol. (Beih. Ergeb. Limnol.) 21: 115-124

Price, H. J., Paffenhöfer, G.-A. (1986a). Capture of small cells by the copepod Eucalanus elongatus. Limnol. Oceanogr. 31 (1): 189-194

Price, H. J., Paffenhöfer, G.-A. (1986b). Effects of concentration on the feeding of a marine copepod in algal monocultures and mixtures. J. Plankton Res. 8(1): 119-128

Price, H. J., Paffenhöfer, G.-A., Strickler, J. R. (1983). Modes of cell capture in calanoid copepods. Limnol. Oceanogr. $28(1): 116-123$

Rosenberg, G. G. (1980). Filmed observations of filter feeding in the marine planktonic copepod Acartia clausii. Limnol. Oceanogr. 25 (4): 738-742

Schnack, S. B. (1982). The structure of the mouth parts of copepods in Kiel Bay. Meeresforsch. 29: 89-101

Singarajah, K. V. (1969). Escape reactions of zooplankton: the

This article was presented by Dr T. Kiorboe, Charlottenlund, Denmark avoidance of a pursuing siphon tube. J. exp. mar. Biol Ecol. 3: 171-178

Sokal, R. R., Rohlf, F. J. (1981). Biometry, 2nd edn. W. H. Freeman and Company, New York

Stearns, D. E., Forward, Jr, R. B. (1984). Photosensitivity of the calanoid copepod Acartia tonsa. Mar Biol. 82: 85-89

Strickler, J. R. (1982). Calanoid copepods, feeding currents, and the role of gravity. Science 218: 158-160

Strickler, J. R. (1984). Sticky water: a selective force in copepod evolution. In: Meyer, D. G., Strickler, J. R. (eds.) Trophic interactions within aquatic ecosystems, AAAS Symposium 85. Westview Press, Boulder, p. 187-239

Tautz, J. (1979). Reception of particle oscillation in a medium an unorthodox sensory capacity. Naturwissenschaften 66 : $452-461$

Vanderploeg, H. A., Paffenhöfer, G.-A. (1985). Modes of algal capture by the freshwater copepod Diaptomus sicilis and their relation to food-size selection. Limnol. Oceanogr $30(4): 871-885$

Wiadnyana, N. N., Rassoulzadegan, F. (1989). Selective feeding of Acartia clausi and Centropages typicus on microzooplankton. Mar. Ecol. Prog. Ser. 53: 37-45

Williamson, C. E. (1987). Predator-prey interactions between omnivorous diaptomid copepods and rotifers: the role of prey morphology and behavior. Limnol. Oceanogr. 32 (1): $167-177$

Wong, C. K. (1988). Effects of competitors, predators, and prey on the grazing behavior of herbivorous calanoid copepods. Bull. mar. Sci. 43 (3) : 573-582

Yen, J. (1985). Selective predation by the carnivorous marine copepod Euchaeta elongata: laboratory measurements of predation rates verified by field observations of temporal and spatial feeding patterns. Limnol. Oceanogr. 30 (3): $577-597$

Yule, A. B., Crisp, D. J. (1983). A study of feeding behaviour in Temora Iongicornis (Muller) (Crustacea: Copepoda). J. exp. mar Biol. Ecol. 71: 271-282

Zaret, R. E., Kerfoot, W. C. (1980). The shape and swimming technique of Bosmina longirostris. Limnol. Oceanogr. 25 (1): 126-133

Manuscript first received: February 23, 1990

Revised version accepted: May 31, 1990 